\title{
Agôn
}

Revue des arts de la scène

Critiques | Saison 2013-2014

\section{Mission de David Van Reybrouck}

Mise en scène de Raven Rüell

\section{Maëline Le Lay}

\section{Q OpenEdition}

Journals

Édition électronique

URL : http://journals.openedition.org/agon/3024

DOI : 10.4000/agon.3024

ISSN : 1961-8581

Éditeur

Association Agôn

Référence électronique

Maëline Le Lay, "Mission de David Van Reybrouck », Agôn [En ligne], Critiques, mis en ligne le 04 avril 2014, consulté le 23 septembre 2020. URL : http://journals.openedition.org/agon/3024 ; DOI : https:// doi.org/10.4000/agon.3024

Ce document a été généré automatiquement le 23 septembre 2020

Association Agôn et les auteurs des articles 


\title{
Mission de David Van Reybrouck
}

\author{
Mise en scène de Raven Rüell
}

\section{Maëline Le Lay}

\section{RÉFÉRENCE}

Mission de David Van Reybrouck dans une mise en scène de Raven Rüell avec Bruno Vanden Broecke, une création du KVS (Koningklijke Vlaamse Schouwburg) de Bruxelles. Spectacle donné au TNBA, Théâtre National de Bordeaux en Aquitaine, du 21 au 25 janvier 2014.

1 Créée en 2007 et rejouée six ans plus tard, Mission s'inscrit dans le sillage de l'œuvre majeure de David Van Reybrouck ${ }^{1}$ et best-seller de la rentrée 2012, Congo. Une histoire. Il paraît évident que le succès de cette pièce qui lui vaut aujourd'hui une tournée européenne, est à lire à l'aune du succès éditorial et médiatique de Congo, tant le cadre de Mission présente a priori peu d'atouts attractifs pour le spectateur lambda: le monologue d'un père blanc, Grégoire, qui raconte sa vie, sa vocation, et ses quarantehuit années passées en République démocratique du Congo, de 1959 à 2007. 
Mission de David Van Reybrouck

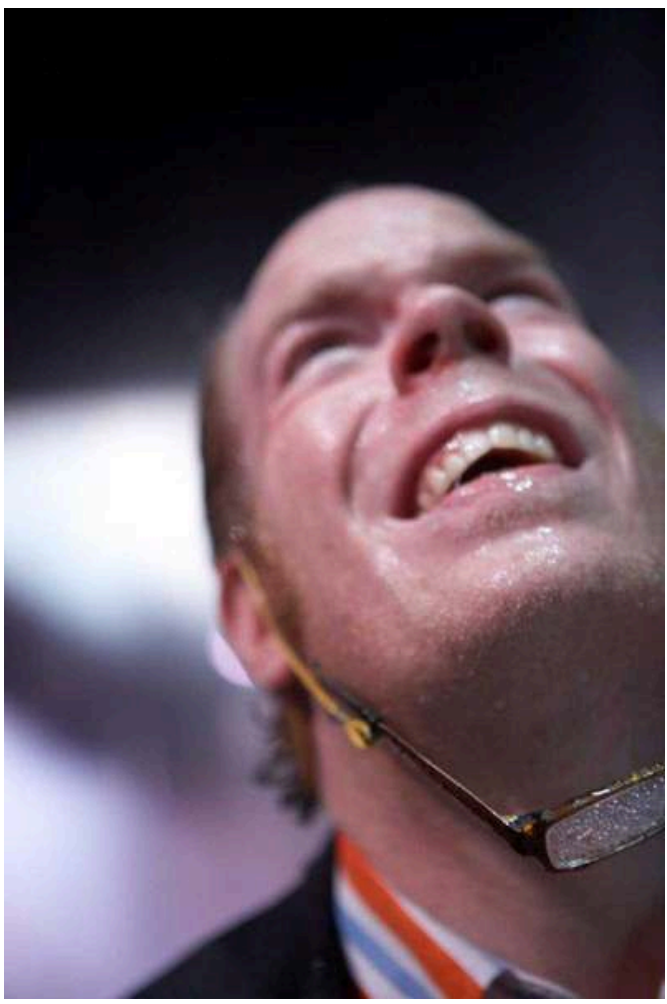

http://www.bellone.be/fra/playdetail.asp?IDfichier=1915044

(c) La Bellone. Maison du spectacle

2 Y sont évoqués l'éducation reçue par ses parents et à l'école, son amour de jeunesse, sa formation ecclésiastique suivie de son départ pour le Congo. De sa vie de missionnaire là-bas passée à l'Est du pays, du Nord Katanga au Kivu, il nous entretient de son travail, de ses amitiés, des guerres qu'il a vécues, de la terreur et des exactions qu'il a vu commettre dans cette région sinistrée par les conflits. Cette anomie meurtrière, David Van Reybrouck la rend plus palpable encore en intégrant dans la trame du monologue un témoignage d'une femme violée. Otage d'un groupe rebelle et réduite à l'esclavage sexuel, sa parole a pour effet d'ancrer le spectacle dans une criante et tragique actualité.

3 Quoiqu'obéissant à un cheminement non-linéaire, le récit demeure fluide et bien rythmé. L'interprétation remarquable de Bruno Vanden Broecke donne du souffle et de l'ampleur au texte tout en respectant le pari - risqué - de la mise en scène minimaliste au possible imaginée par l'auteur. Père Grégoire reste statiquement posté derrière un pupitre pendant les deux heures que dure le spectacle.

4 La mise en scène obéit donc à cette grande sobriété jusqu'à l'orage final annoncé par un formidable coup de tonnerre. Prenant le spectateur par surprise, il semble déclenché par le cri de désespoir et de colère du personnage dont l'humeur débonnaire était jusque-là égale: «Dieu!» tonne-t-il subitement. Une pluie diluvienne se met alors à tomber, le trempant des pieds à la tête. Puis, le rideau de fond de scène se lève, découvrant des rangées de chaises en plastique vides disposées face au public au-dessus desquelles planent de grands et bas néons, certains gisants à terre. Trempé, dépenaillé et hagard, l'acteur, après avoir cajolé le cadavre d'une effigie de rapace, le dépose lentement sur son pupitre et s'assoit péniblement sur une chaise, aux pieds d'une 
grande peluche de léopard couchée sur le flanc. Comment interpréter cet étrange tableau? Le personnage hébété errant dans un Congo ravagé par les guerres et les dictatures, déserté par la foi qu'il s'efforce pourtant de ressusciter ?...

Quelle qu'en soit l'interprétation, cette scène apocalyptique où la surenchère d'effets scéniques (cacophonie, explosion de lumière, trombes d'eau sur le plateau et humidité diffuse dans la salle) le dispute à un symbolisme pesant tranche singulièrement avec le reste. Et la justesse du ton de l'ensemble, portée par ce personnage de missionnaire dépeint sous un jour tout à fait sympathique s'en trouve comme altérée.

Tout est fait pour que le spectateur le trouve attachant et puisse ainsi s'identifier à lui : l'aveu de ses faiblesses comme les jeux d'interaction avec les spectateurs. Car finalement c'est surtout de nous dont il nous entretient, nous qui vivons ici dans cette Europe prospère, et à qui il est venu parler. $Y$ sont justement dépeints les travers de nos contemporains : l'impatience et la vitesse, l'avidité obsessionnelle et la compétitivité : «Ils veulent tout, tout de suite et provisoirement! Alors, c'est sûr, c'est pas facile, hein... $»^{2}$. Du refus de faire des choix décisifs aujourd'hui, de l'incapacité à s'engager, il en est question à plusieurs reprises dans le monologue de Père Grégoire. Ainsi si le personnage répète : "nous on a choisi, hein ", ce n'est pas pour s'ériger en modèle et faire du choix un acte définitif et imprescriptible. Bien au contraire, il conçoit le choix comme une direction que l'on ne doit pas se lasser de reprendre : « un choix, c'est un écho qui s'intensifie. À chaque fois un peu plus fort. On ne choisit pas une fois, on choisit tant de fois. Et à la fin, on appelle ça une vie $»^{3}$.

\section{NOTES}

1. David Van Reybrouck, Mission suivi de L'âme des termites, Arles, Actes Sud Papiers, 2011. Pièces traduites par Monique Nagielkop, d'après les textes originaux en néerlandais, Missie (écrit et mis en scène en 2007 au KVS de Bruxelles par Raven Rüell avec Bruno Vanden Broecke) et Die Siel van die Mier (écrit en 2004).

2. Adapté du texte original en traduction française : « Mais non, ils veulent tout, tout de suite et encore bien. Et de préférence, pas pour toujours » : David Van Reybrouck, Mission, op.cit., p. 45-46. 3. David Van Reybrouck, Mission, op.cit., p. 43, repris sur la $1^{\text {ère }}$ de couverture de la brochure de Mission au TNBA. 